\title{
Manual Lymphatic Drainage Ccombined with Functional Exercise in the Treatment of Lymphedema After Modified Radical Mastectomy
}

\author{
Li Shiting, Ma Yuhua* \\ Email address: \\ lishiting2019@126.com (Ma Yuhua) \\ ${ }^{*}$ Corresponding author
}

Department of Thyroid and Breast Surgery, The First Affiliated Hospital of Jinan University, Guangzhou, China

To cite this article:

Li Shiting, Ma Yuhua. Manual Lymphatic Drainage Ccombined with Functional Exercise in the Treatment of Lymphedema After Modified Radical Mastectomy. American Journal of Nursing Science. Vol. 8, No. 6, 2019, pp. 351-355. doi: 10.11648/j.ajns.20190806.20

Received: November 24, 2019; Accepted: December 9, 2019; Published: December 18, 2019

\begin{abstract}
Objective We aim to investigate the effect of manual lymphatic drainage in combination with functional exercise in the recovery from modified radical mastectomy. The outcome measurements are the incidence of lymphedema, function of upper limb, pain and life quality after operation. Methods We included 198 patients diagnosed with breast cancer in pathological examination and having received modified radical mastectomy in the First Affiliated Hospital of Jinan University from January 2016 to December 2017. The patients were randomized into experimental and control groups with 99 cases in each group. The control group was given guidance on functional exercise and health education. The control group, based on the treatment of control group was also given manual lymphatic drainage and the patients or their family members were ensured to master the practice of manual lymphatic drainage so that they could perform it after discharge. The incidence of lymphedema, pain, range of motion of shoulder joint and life quality among patients at three, six, twelve months postoperatively were recorded. Results There was no significant difference in the incidence of lymphedema at three months after operation $(\mathrm{P}<0.05)$ while there was significant difference in the incidence of lymphedema, range of motion of shoulder joint, pain score and life quality at six and twelve months postoperatively between the two groups $(\mathrm{P}>0.05)$. Conclusions Manual lymphatic drainage in combination with functional exercise is effective to reduce the incidence of lymphedema, difficulty in motion of shoulder joint and pain and numbness of affected limb, and improve life quality after breast cancer operation.
\end{abstract}

Keywords: Breast Cancer, Manual Lymphatic Drainage, Functional Exercise, Life Quality

\section{Introduction}

Breast cancer has become the most common malignant tumor among women with an incidence of around 35-44/ 100000 every year [1]. China is now one of the countries of fastest growing incidence of breast cancer [2]. So far operation is still the major treatment for primary invasive breast cancer [3], and mastectomy is adopted by most in that it can remove the lesion, maximizing the possibility of curing the cancer. However, lymphedema is very likely to occur in the upper limb of the affected side because axillary lymph node dissection in mastectomy and radiotherapy for local lesion destroy the lymphatic vessel net. It is reported that the incidence of lymphedema after breast cancer operation is
$16 \%-50 \%[4,5]$. If intervention is not taken for lymphedema, patients have to suffer from appearance problem, upper limb pain in the affected side, edema, fatigue, repeated infection, tumidness, upper lib dysfunction and psychological disorder, reducing patients' life quality [6]. Therefore, early intervention is important to reduce the lymphedema-induced symptoms and incidence of later complications. Our department provide manual lymphatic drainage and postoperative functional exercise for patients having received modified radical mastectomy to promote the return of lymph stagnated in the breast tissue, relieve the lymphedema of upper limb after modified radical mastectomy and improve patients' life quality. 


\section{Data and Methods}

\subsection{General Data}

We included 198 patients who were diagnosed with breast cancer in pathological examination and were given axillary lymph node dissection in the First Affiliated Hospital of Jinan University from January 2016 to December 2017. Among the 198 patients, 134 of them were with II stage breast cancer and the other 64 were with III stage breast cancer. We used random number table to randomize the 198 patients into two groups: experimental group (99 patients) and control group (99 patients). The inclusion criteria are: 1) having received modified radical mastectomy (including mastectomy and axillary lymph node dissection); 2) before operation having no edema in both upper limbs which function well; 3) having given their informed consent to this research; 4) accepting treatment of manual lymphatic drainage. The exclusion criteria are: 1) having not received axillary lymph node dissection; 2) having edema in one or both upper limbs before operation; 3) having upper limb dysfunction prior to operation; 4) having advanced breast cancer with multiple systemic metastasis; 5) having cognitive behavior disorder.

\subsection{Methods}

\subsubsection{Control Group}

We provided for patients in control group measures for preventing lymphedema and daily self-caring based on the 18 guidelines on the prevention of upper limb lymphedema by National Lymphedema Network (NLN) in 2003 [7]. We also instructed patients on functional exercise for the upper limb in the affected side: at 1-3 days after modified radical mastectomy, put the affected upper limb before the chest and then make hand-clenching movements and rotate wrist joint for two rounds per day and 50 times per round; from the fourth day till the day when the axillary drainage tube is removed after operation, make elbow flexion movement, moving the forearm while keeping the upper arm still for two rounds a day and 10 minutes per round; at the first day after removing the drainage tube, patents without seepage from the wound begin to do the six sessions of functional training exercise. In the first session, patients need to straighten the affected upper limb as much as possible and make hand-clenching movements. In the second session, patients tried to straighten the affected upper limb and make elbow flexion movements. The third session is shoulder joint rotation: first 360 degrees forward and 360 degrees backward. In the fourth session, patients are required to use the healthy hand to grab hold of the affected hand and lift it from the bottom up. The fifth session is designed to touch the ear and the sixth session asks the patients to simulate climbing a wall. The functional training exercise should be done twice a day and four eight-beat rounds once step by step. Hence, patients in the control group had functional exercise for affected limb and health education which are regular nursing intervention.

\subsubsection{Experimental Group}

Besides the intervention mentioned for the control group, patients in the experimental group also received manual lymphatic drainage [8]. The instructions on the manual lymphatic drainage are as follows: The patients assumed a supine position with the affected limb and the long axis of heart in parallel. Gentle press and massage were performed following the distribution of the superficial lymphatic system and the paths of lymphatic return. The order of the performance is as follows: 1) pressing the regional lymph nodes namely supraclavicular fossa, axilla of the unaffected side and groin; 2) massage from the torso part of the unaffected side to axilla along the trend of the lymphatic vessels; 3) drainage for the torso and limb of the affected side to promote the lymphatic return to the limb of the affected side through normal lymphatic pathways. The operation principles include: 1) the skin is touched by hand and pressure is light and alternating; 2) massage is done in the desired direction of lymph movement and from proximal part to distal end; 3 ) the movement should be slow and rhythmic. Manual lymphatic was performed by a professional nurse who has received standardized training on performance of manual lymphatic drainage after the wound healed. Stationary Circles, Compression Pump, Scoop Technique, and Rotary Technique were adopted to promote lymphatic return. The nursing staff first showed how to perform and for the second time instructed patients and their family members. The manual lymphatic drainage was performed three times per day and 10-15 minutes once. When leaving the hospital, the patients' or their family's performance were evaluated to ensure that they had mastered the manual lymphatic drainage and could effectively perform it at home.

\subsection{Evaluation Methods}

The incidence of lymphedema, range of motion of shoulder joint, pain of the affected limb and life quality of the two groups before intervention, at 3, 6, 12 months after intervention were investigated.

\subsubsection{Incidence and Evaluation of Lymphedema}

Circumference measurement was employed. (1) Mild edema: the circumference of the most serious part of the affected upper limb is less than $3 \mathrm{~cm}$ thicker than that of the healthy arm, and the mild edema is usually limited to the proximal end of the limb; (2) moderate edema: the circumference of the most serious part of the affected upper limb is $3-6 \mathrm{~cm}$ thicker than that of the healthy limb, and the moderate edema usually spreads to the whole upper limb including forearm and the back of the hand; (3) severe edema: the circumference of the most serious part of the affected upper limb is over $6 \mathrm{~cm}$ thicker than that of the healthy arm. Severe edema causes hardness to the skin and impacts he whole upper limb including fingers, resulting in limited motion of shoulder joint. The locations at which to measure the circumference of the upper limbs: at wrist, $8 \mathrm{~cm}$ above transverse carpal crease, elbow, $8 \mathrm{~cm}$ below and above transverse cubital crease, $8 \mathrm{~cm}$ below shoulder joint [9]. 


\subsubsection{Range of Motion of Shoulder Joint}

The range of motion of shoulder joint was measured with protractor at 3, 6, 12 months postoperatively. It is considered as appropriate when the patient has no pain or discomfort in the upper limb of the affected side. Clinic evaluation: excellent: shoulder extension $40-50^{\circ}$, internal and external rotation $90^{\circ}$, abduction $160-180^{\circ}$, flexion $160-180^{\circ}$; good: shoulder extension $30-90^{\circ}$, internal and external rotation $90^{\circ}$, abduction $140-159^{\circ}$, flexion $140-159^{\circ}$; ordinary: shoulder extension $<30^{\circ}$, internal and external rotation $90^{\circ}$, abduction $<140^{\circ}$, flexion $<140^{\circ}[10]$.

\subsubsection{Evaluation of Life Quality}

The questionnaire EORCT QLQ-C30 made by European Organization for Research and Treatment of Cancer was used to evaluate patients life quality from 5 perspectives namely physical, role, emotional, social and cognitive functions [11]. The higher the standardized score is, the better the function is.

\subsubsection{Pain in the Affected Limb}

Numerical rating scale (NRS) was used to evaluate the severity of pain. The scale range from 0 to 10 scores. 0 is no pain, $1-3$ is mild pain, 4-6 is moderate pain and 7-10 is severe pain.

\subsection{Statistical Analysis}

SPSS20. 0 was used for analysis. Chi-square test or Fisher's Exact Test is adopted for comparison of rates and t-test for measurement data. $\mathrm{P}<0.05$ indicates that the difference is significant.

\section{Results}

\subsection{Baseline Data of Experimental Group and Control Group}

The average age of experimental group is (47 \pm 17$)(28-70)$ while that of the control group is (48土18) (29-69). The average body mass index (BMI) of the experimental group is (22.24 \pm 5.08$)(18.26-26.45)$ and the average BMI of control group is $(22.39 \pm 5.37) \quad(17.46 \sim 28.19)$. The eliminated lymph nodes range from 15 to 36 in the experimental group with an average of $(19 \pm 7)$ and 12 36 in the control group with an average of $(18 \pm 8)$. There was no significant difference in the baseline value between the two groups (as shown in Table 1).

Table 1. Baseline Data of the Experimental Group and Control Group.

\begin{tabular}{lllll}
\hline Group & Case & Age & BMI & Number of eliminated lymph nodes \\
\hline Experimental group & 99 & $47 \pm 17$ & $22.24 \pm 5.08$ & $19 \pm 7$ \\
Control group & 99 & $48 \pm 18$ & $22.39 \pm 5.37$ & $18 \pm 8$ \\
P & & 0.466 & 0.83 & 0.08 \\
\hline
\end{tabular}

\subsection{Incidence of Lymphedema}

The difference in the incidence of lymphedema at 3 months after operation between experimental group and control group is of no statistical significance $(\mathrm{P}>0.05)$ while it is statistically significant at 6,12 months $(\mathrm{P}<0.05$, as shown in Table 2$)$.

Table 2. Cases of Lymphedema after Operation.

\begin{tabular}{|c|c|c|c|c|c|c|c|c|c|c|}
\hline \multirow{2}{*}{ Group } & \multirow{2}{*}{ Case } & \multicolumn{3}{|c|}{3 months postoperatively } & \multicolumn{3}{|c|}{6 months postoperatively } & \multicolumn{3}{|c|}{12 months postoperatively } \\
\hline & & Mild & Moderate & Severe & Mild & Moderate & Severe & Mild & Moderate & Severe \\
\hline Experimental group & 99 & 4 & 2 & 0 & 8 & 2 & 1 & 10 & 6 & 2 \\
\hline Control group & 99 & 6 & 3 & 0 & 4 & 6 & 7 & 6 & 8 & 11 \\
\hline$x^{2}$ & & 0 & & & 6.86 & & & 6.55 & & \\
\hline $\mathrm{P}$ & & 0.706 & & & 0.032 & & & 0.038 & & \\
\hline
\end{tabular}

\subsection{Range of Motion of Shoulder Joint}

The range of motion of shoulder joint of the experimental group is better than that of the control group with significant difference as shown in Table 3.

Table 3. Range of Motion of Shoulder Joint of Two Groups (n [case]/\%).

\begin{tabular}{|c|c|c|c|c|c|c|c|c|c|c|}
\hline \multirow{2}{*}{ Group } & \multirow{2}{*}{ Case } & \multicolumn{3}{|c|}{3 months postoperatively } & \multicolumn{3}{|c|}{6 months postoperatively } & \multicolumn{3}{|c|}{12 months postoperatively } \\
\hline & & Excellent & Good & Ordinary & Excellent & Good & Ordinary & Excellent & Good & Ordinary \\
\hline Experimental group & 99 & 31 & 42 & 26 & 50 & 41 & 8 & 60 & 30 & 9 \\
\hline Control group & 99 & 15 & 40 & 44 & 30 & 62 & 7 & 40 & 45 & 14 \\
\hline$x^{2}$ & & 10.243 & & & 9.348 & & & 8.087 & & \\
\hline $\mathrm{P}$ & & 0.006 & & & 0.009 & & & 0.018 & & \\
\hline
\end{tabular}

\subsection{Pain Score}

Pain scores of the experimental group at 3 months, 6 months and 12 months postoperatively are lower than those of the control group with significant difference $(\mathrm{P}<0.05$, as shown in Table 4$)$. 
Table 4. Pain Scores of Two Groups.

\begin{tabular}{lllll}
\hline Group & Case & 3 months postoperatively & 6 months postoperatively & 12 months postoperatively \\
\hline Experimental group & 99 & $2.14 \pm 1.28$ & $1.94 \pm 1.19$ & $1.88 \pm 1.21$ \\
Control group & 99 & $3.65 \pm 1.29$ & $3.14 \pm 1.21$ & $2.88 \pm 131$ \\
P & & 0.0037 & 0.006 & 0.046 \\
\hline
\end{tabular}

\subsection{Life Quality Score}

There is significant difference in the life quality score at 3,6,12 months postoperatively between experimental and control groups $(\mathrm{P}<0.05)$ as shown in Table 5 .

Table 5. Life Quality Score of Two Groups.

\begin{tabular}{|c|c|c|c|c|c|c|c|c|c|c|}
\hline \multirow[b]{2}{*}{ Group } & \multirow[b]{2}{*}{ Case } & \multicolumn{3}{|c|}{ Physical function } & \multicolumn{3}{|c|}{ Role function } & \multicolumn{3}{|c|}{ Emotional function } \\
\hline & & $\begin{array}{l}3 \text { months } \\
\text { postoperati } \\
\text { vely }\end{array}$ & $\begin{array}{l}6 \text { months } \\
\text { postoperati } \\
\text { vely }\end{array}$ & $\begin{array}{l}12 \text { months } \\
\text { postoperati } \\
\text { vely }\end{array}$ & $\begin{array}{l}3 \text { months } \\
\text { postoperati } \\
\text { vely }\end{array}$ & $\begin{array}{l}6 \text { months } \\
\text { postoperati } \\
\text { vely }\end{array}$ & $\begin{array}{l}12 \text { months } \\
\text { postoperati } \\
\text { vely }\end{array}$ & $\begin{array}{l}3 \text { months } \\
\text { postoperati } \\
\text { vely }\end{array}$ & $\begin{array}{l}6 \text { months } \\
\text { postoperati } \\
\text { vely }\end{array}$ & $\begin{array}{l}12 \text { months } \\
\text { postoperati } \\
\text { vely }\end{array}$ \\
\hline Exper & 99 & $79 \pm 9$ & $80.34 \pm 12$ & $90.12 \pm 7$ & $73.12 \pm 5$ & $75.87 \pm 7$ & $79.25 \pm 11$ & $75.25 \pm 4.5$ & $76 \pm 6.12$ & $79.37 \pm 11$ \\
\hline Control & 99 & $71.13 \pm 10.3$ & $76.25 \pm 11$ & $84.25 \pm 8$ & $72.25 \pm 4$ & $63.12 \pm 6.8$ & $75.625 \pm 9$ & $69.37 \pm 3.8$ & $72 \pm 8.1$ & $74.87 \pm 11$ \\
\hline$P$ & & 0.014 & 0.021 & 0.02 & 0.023 & 0.01 & 0.023 & 0.275 & 0.029 & 0.004 \\
\hline
\end{tabular}

Table 5. Continued.

\begin{tabular}{llllllll}
\hline \multirow{2}{*}{ Group } & \multirow{2}{*}{ Case } & Social function & & \multicolumn{3}{l}{ Cognitive function } \\
\cline { 3 - 8 } & & $\begin{array}{l}\text { 3 months } \\
\text { postoperatively }\end{array}$ & $\begin{array}{l}\text { 6 months } \\
\text { postoperatively }\end{array}$ & $\begin{array}{l}\text { 12 months } \\
\text { postoperatively }\end{array}$ & $\begin{array}{l}\text { 3 months } \\
\text { postoperatively }\end{array}$ & $\begin{array}{l}\text { 6 months } \\
\text { postoperatively }\end{array}$ & $\begin{array}{l}\text { 12 months } \\
\text { postoperatively }\end{array}$ \\
\hline Experimental & 99 & $75.25 \pm 5.1$ & $76.12 \pm 5.4$ & $78 \pm 4.8$ & $57.37 \pm 1.25$ & $63.25 \pm 6.1$ & $68.25 \pm 5.1$ \\
Control & 99 & $69.62 \pm 6.1$ & $71.37 \pm 4.9$ & $72.25 \pm 4.1$ & $48.25 \pm 3.4$ & $57.12 \pm 3.6$ & $61.25 \pm 4.6$ \\
P & & 0.011 & 0.010 & 0.000 & 0.04 & 0.033 & 0.389 \\
\hline
\end{tabular}

\section{Discussion}

Breast cancer is of high incidence among women and operation is still the major treatment for it. However, lymphatic dissection in the operation inevitably obstructs lymphatic return and at the same time due to ligation of cephalic vein, blood return is also obstructed. Obstruction of return of lymph and blood plus seepage and accumulation of interstitial fluid lead to post-operative lymphedema of the affected limb [12]. The edema of the affected upper limb is one of the common complications of modified radical mastectomy. Edema, deformation and numbness have a strong impact on patients life quality. In recent years, manual lymphatic drainage has been recommended as a standard treatment for lymphedema. Scholars at home and abroad also propose guidelines for early detection, early prevention and management of lymphedema [13]. The incidence of lymphedema in breast cancer shows an increasing trend within 2 years after surgery [14]. If we do not take active intervention, lymphedema may develop into chronic lymphedema which will spread to other parts and is harder to treat. Therefore, active prevention and treatment of upper limb lymphedema is crucial to improve patients health and quality of life after surgery. The current research explores practicable early intervention measurements to prevent or reduce the occurrence of postoperative lymphedema.

The control group was given instructions on prevention and self-caring measurements for lymphedema based on the 18 guidelines for prevention of upper limb lymphedema proposed by NLN in 2003. At the same time, patients were instructed to do functional exercise for affected limb. Moderate movements and exercise are conducive to promoting lymph circulation and stimulating muscle contraction so as to push lymph to move toward heart through the work of valve, which will further promotes the return of lymph [15]. The experimental group, besides the intervention of the control group, also received manual lymphatic drainage. We found that the incidence of lymphedema after surgery of the experimental group was lower than that of the control group. Manual lymphatic drainage is a massage for superficial lymph nodes and lymphatic network. It pushes the accumulated lymph fluid back into the blood by opening the lymph nodes and massaging the lymphatic vessels, promoting the return of lymph fluid, improving the function of normal lymphatic vessels, and allowing lymph fluid to bypass the failed or blocked lymphatic vessels so as to prevent the occurrence and development of lymphedema. The results of this study show that postoperative functional exercise combined with manual lymphatic drainage can effectively reduce lymphedema in breast cancer patients.

The function of affected limb of patients in the experimental group is obviously better than that of the control group with significant difference $(\mathrm{P}<0.05)$. Research at home suggests that patients with breast cancer undergo early and progressive functional exercise after operation, and make finger joints, wrist joints, elbow joints and shoulder joints movement at different stages. Long-term adherence to functional exercise can promote muscle movement and vascular pulsation, accelerating lymph fluid. Some scholars also believe that manual lymphatic drainage combined with functional exercise can effectively alleviate the pain of the affected limb, improve 
the functional exercise compliance of the affected limb, and promote the recovery of the affected limb [16]. These findings are consistent with the results of the current research.

The results of this study show that the five functional dimensions of quality of life: physical function, role function, emotional function, social function, cognitive function of experimental group having received manual lymphatic drainage in combination with functional exercise are superior to those of the control group 3 months, 6 months, and 12 months postoperatively and the difference was statistically significant $(\mathrm{P}<0.05)$. Manual lymphatic drainage combined with functional exercise effectively relieve pain in the affected limb of patients in the experimental group. The results show that the pain score of experimental group is significantly lower than that of the control group with significant difference.

\section{Conclusions}

In conclusion, the method of combining manual lymphatic drainage with functional exercise is simple and easy to perform. Our study shows that this method can effectively reduce the incidence of lymphedema, shoulder joint movement disorder, pain and numbness of the affected limb after breast cancer operation, improving the quality of life. However, the sample size of this study is small, and the period of follow-up is short. For the prevention and treatment of lymphedema of affected limb after modified radical mastectomy and the intervention and of postoperative pain and dysfunction of affected limb, further long-term follow-up and observation are needed.

\section{Acknowledgements}

This work was financially supported by the Guangdong Provincia Medical Science and Technology Research Fund Project (NO. A2016165).

\section{References}

[1] Desantis, C. E., Ma, J., Gaudet, M. M., Newman, L. A., Miller, K. D., \& Sauer, A. G., et al. (2019). Breast cancer statistics, 2019. CA: A Cancer Journal for Clinicians, 69 (suppl 12), 7-34.

[2] Hua, Alexandra, Sesto, Mary E., Zhang, Xiao, Wassenaar, Timothy R., \& Tevaarwerk, Amye J. (2019). Impact of survivorship care plans and planning on breast, colon, and prostate cancer survivors in a community oncology practice. Journal of Cancer Education (11), 1-7.

[3] Smoot, B., Kober, K. M., Paul, S. M., Levine, J. D., Abrams, G., \& Mastick, J., et al. (2017). Potassium channel candidate genes predict the development of secondary lymphedema following breast cancer surgery. Nursing Research, 66 (2), 85-94.

[4] Shao, Y., \& Zhong, D. S. (2016). Manual lymphatic drainage for breast cancer-related lymphoedema. European Journal of Cancer Care. 13 (5): 12517-12532.
[5] Disipio, T., Rye, S., Newman, B., \& Hayes, S. (2013). Incidence of unilateral arm lymphoedema after breast cancer: a systematic review and meta-analysis. The Lancet Oncology, 14 (6), 500-515.

[6] Pusic, A. L., Cemal, Y., \& Claudia Albornoz.... (2013). Quality of life among breast cancer patients with lymphedema: a systematic review of patient-reported outcome instruments and outcomes. Journal of Cancer Survivorship, 7 (1), 83-92.

[7] Kang, Y., Jang, D. H., Jeon, J. Y., Lee, S. J., Jeong, S. Y., \& Shin, D. I., et al. (2012). Pressure monitoring of multilayer inelastic bandaging and the effect of padding in breast cancerrelated lymphedema patients. American Journal of Physical Medicine \& Rehabilitation, 91 (9), 768-773.

[8] Ezzo, J., Manheimer, E., Mcneely, M. L., Howell, D. M., \& Karadibak, D. (2015). Manual lymphatic drainage for lymphedema following breast cancer treatment. Cochrane database of systematic reviews, 21 (5), CD003475.

[9] Uzkeser, H., Karatay, S., Erdemci, B., Koc, M., \& Senel, K. (2015). Efficacy of manual lymphatic drainage and intermittent pneumatic compression pump use in the treatment of lymphedema after mastectomy: a randomized controlled trial. Breast Cancer, 22 (3), 300-307.

[10] Galantino, ML., Stout, NL.(2013).Exercise interventions for upper limb dysfunction due to breast cancer treatment. Phys Ther. 2013, 93 (10), 1291-7.

[11] Sat-Muñoz, D., Contreras-Hernández, I., Balderas-Peña, L. M., Hernández-Chávez, G. A., Solano-Murillo, P., \& Mariscal-Ramírez, I., et al. (2011). [quality of life in mexican women with breast cancer at different stages and its association with sociodemographic characteristics, comorbidities and procedural factors at the mexican institute of social security]. Value in Health, 14 (5 Suppl 1), S133-6.

[12] Bozkurt, M., Palmer, L. J., \& Guo, Y. (2017). Effectiveness of decongestive lymphatic therapy in patients with lymphedema resulting from breast cancer treatment regardless of previous lymphedema treatment. Breast Journal, 23 (2), 154-158.

[13] De, O. M. M. F., Costa, G. M. S., Amorim Bárbara Juarez, Dario, R. C., Sophie, D., \& Natachie, F. S., et al. (2018). Long term effects of manual lymphatic drainage and active exercises on physical morbidities, lymphoscintigraphy parameters and lymphedema formation in patients operated due to breast cancer: a clinical trial. PLOS ONE, 13 (1), e0189176.

[14] Norman, S. A., Localio, A. R., Potashnik, S. L., Simoes Torpey, H. A., Kallan, M. J., \& Weber, A. L., et al. (2008). Lymphedema in breast cancer survivors: incidence, degree, time course, treatment, and symptoms. Journal of Clinical Oncology, 27 (3), 390-397.

[15] Rupp, J., Hadamitzky, C., Henkenberens, C., Christiansen, H., Steinmann, D., \& Bruns, F. (2019). Frequency and risk factors for arm lymphedema after multimodal breast-conserving treatment of nodal positive breast cancer-a long-term observation. Radiation Oncology, 14 (1), 39.

[16] Bhatt, N. R., Boland, M. R., Mcgovern, R., Lal, A., Tormey, S., \& Lowery, A. J., et al. (2017). Upper limb lymphedema in breast cancer patients in the era of z0011, sentinel lymph node biopsy and breast conservation. Ir J Med Sci, 187 (2), 1-5. 